ESPAÇO TEMÁTICO: ESTADO, AUTORITARISMO E LUTA DE CLASSES

\title{
Estado e classes sociais: uma imbricada e contraditória relação
}

\author{
Liliam dos Reis Souza Santos ${ }^{1}$ \\ https://orcid.org/0000-0001-6410-6371 \\ ${ }^{1}$ Universidade de Brasília, Departamento de Serviço Social, Brasília, DF, Brasil
}

\section{Estado e classes sociais: uma imbricada e contraditória relação}

Resumo: Este artigo analisa a relação Estado e classes sociais no capitalismo. Evidencia a natureza contraditória, relacional e de classe do Estado. Atrela as determinações da relação Estado-classes sociais à dinâmica produtiva capitalista, à dominação e à luta política. Apresenta também as ações desempenhadas pelo Estado na inter-relação com as classes sociais, com o objetivo de manter a dominação das classes subalternas e a hegemonia das classes dominantes.

Palavras-chave: Estado. Classes Sociais. Capitalismo.

\section{State and social classes: an overlapping and contradictory relationship}

Abstract: The article theoretically reflects on the interaction between state and social classes in capitalism. It shows the contradictory, relational and class nature of the state. It links the determinations of the relationship between state and social classes to capitalist productive dynamics, domination and political struggle. It also presents the actions performed by the State in the interrelationship with social classes, with the objective of maintaining the domination of the subordinate classes and the hegemony of the ruling classes.

Keywords: State. Social classes. Capitalism.

Recebido em 18.05.2020. Aprovado em 22.06.2020. Revisado em 11.09.2020. 


\section{Introdução}

A pretensão deste artigo é abordar a complexa, dinâmica e contraditória relação entre o Estado capitalista e as classes sociais fundamentais desse sistema, em busca de evidenciar essa interação como uma das principais mediações desenvolvidas pelo Estado para a sustentação do modo de produção capitalista.

Nesse sentido, cabe ressaltar que o processo de desenvolvimento histórico do capitalismo favoreceu a estruturação de um sistema social baseado em aparente dissociação entre as esferas política e econômica, configurando um estatuto cívico particular que primava por princípios de igualdade política, mas sem que esta implicasse na desigualdade econômica, assentada na exploração do trabalho.

A despolitização das relações produtivas contribui para a construção do chamariz ideológico de que o Estado estava acima das classes capitalistas fundamentais: burguesia e trabalhadora. Esse desenho foi favorável à construção de uma compreensão imparcial do Estado capitalista, que tem por referência um padrão formal e limitado de democracia e cidadania.

Todavia, essa percepção, longe de representar a ausência de participação do Estado nas atividades produtivas, revela uma fase mais avançada e complexa de relação orgânica entre as esferas econômicas e políticas, uma fase em que, com o Estado burguês, se estruturou um sistema de dominação política que retira da classe dominante a primazia da coerção. Esta dominação, agora mediada pelo Estado, apresenta-se como um poder soberano, acima das classes, neutralizando os conflitos entre capital e trabalho.

Tem-se, assim, um poder político sem precedentes que, supostamente apartado das relações econômicas, configura-se como uma estratégia de dominação impessoal, mediante a qual o espaço político, por excelência, foi privatizado pelo metabolismo do capital. Nesta interação com as classes sociais, o Estado desempenha variadas funções em prol da hegemonia do sistema.

Ainda que predomine a sua condição de classe, cabe ressaltar que o Estado capitalista não pode ser compreendido como um exclusivo burguês, justamente porque, nessa dinâmica, o Estado é atravessado pelas lutas de classe e responde de maneira contraditória à essas lutas, ao mesmo tempo em que as condensa. Esses elementos evidenciam uma natureza relacional contraditória do Estado, conforme debate a seguir.

\section{Estado, classes sociais e sociedade civil: eixos aparentemente apartados, mas essencialmente imbricados}

A relação entre Estado e classes sociais não é uma novidade do capitalismo, mas uma marca da trajetória de desenvolvimento das relações sociais, especialmente nas sociedades em que as atividades produtivas são atravessadas pela exploração e dominação. Estas injunções desencadeiam uma polarização social ou uma divisão em classes, essencialmente antagônicas, posto que marcadas por um confronto inerente no qual predomina o domínio de uma sobre a outra.

Em resposta a essa polarização e a esses conflitos, surgiu o ordenamento político representado pelo Estado. Assim, "onde existe divisão de classes, há, portanto, luta e poder de classe, existe o Estado, o poder político institucionalizado". (POULANTZAS, 1980, p. 45).

Entretanto, o Estado não emerge como uma instituição neutra, mas como expressão do domínio político e social da classe dominante. Assim, "damos o nome de Estado apenas quando esta tarefa está atravessada pelas funções de dominação e poder de classes sociais". (OSORIO, 2019, p. 19).

No capitalismo, cabe reiterar, o Estado oculta seu caráter de classe, apresentando-se como um Estado de todos e promotor do bem comum. Isso se deve às características das relações produtivas desse sistema, marcadas por uma relativa separação entre a esfera política e econômica, como consequência do relativo afastamento do Estado dos meios de produção e das relações produtivas, desenhando um modelo político que parece distanciado das relações econômicas e das lutas de classes.

Aparentemente, o Estado se cristaliza, nesse processo, como uma instituição independente, imparcial e autônoma em relação às classes sociais e, assim, a relação de compra e venda da força de trabalho e os processos de extração da mais-valia se apresentam alheios às ações políticas.

Em contraposição a essa interpretação superficial, considera-se que as classes sociais não são um elemento exterior a um perfil de Estado impenetrável, mas, sim, seu constituinte orgânico, sem, contudo, reduzir um ao 
outro: "o Estado tem um papel constitutivo na existência e reprodução dos poderes de classe, e em especial na luta de classes, o que explica a sua presença nas relações de produção". (POULANTZAS, 1980, p. 43).

Para além das determinações relacionadas às dinâmicas produtivas, a relação Estado x classes sociais é determinada pelos aspectos de dominação e de luta política, que não são variantes ou exteriores ao Estado, mas constituinte da sua ossatura institucional. Desse modo, "se as lutas políticas que ocorrem no Estado atravessam seus aparelhos, é porque essas lutas estão desde já inscritas na trama do Estado do qual elas esboçam a configuração estratégica". (POULANTZAS, 1980, p. 162).

Juntamente com a sua compleição constituída das classes sociais, o Estado também constitui estas classes, particularmente a dominante. Ele tem "um papel orgânico na luta e na dominação políticas". No capitalismo, "o Estado capitalista constitui a burguesia como classe dominante". Isso significa que este "tem uma natureza de classe", que está inscrita na sua materialidade institucional, não sendo, portanto, um apêndice de dominação situado fora do sistema (POULANTZAS, 1980, p. 144-145).

A natureza de classe do Estado dessacraliza-o do seu perfil formal e autônomo, reproduzido como uma instituição evolucionista e natural, dissociada das contradições da sociedade. Determinado e determinante das classes sociais, ao Estado cabe conservar e reproduzir essas classes, mas com vista a manter os interesses e privilégios da classe dominante, garantindo que os interesses desta classe sejam impostos como interesse geral.

A natureza de classe do Estado desconstrói a tese de sua separação da sociedade civil, já que ele, sendo elemento de produção e reprodução das relações sociais capitalistas e da opressão de classe, é parte da sociedade civil e, dessa forma, impotente para mudá-la. Ao contrário, ele atua para mantê-la, pois ambos são momentos distintos de um mesmo processo. Assim, "as raízes do poder estatal acham-se na sociedade civil" (IANNI, 1986, p. 124), da qual faz parte.

As mediações do Estado no processo de dominação de classes e garantia da hegemonia da classe dominante, não fica restrito aos aspectos legais e jurídicos, mas também se respalda em estratégias de consenso e consentimento. É na sociedade civil que as relações sociais se naturalizam e legitimam e sobre as quais o Estado capitalista se fundamenta. Nela se "produzem e difundem as representações ideológicas" e é o espaço em que "as classes buscam exercer sua hegemonia, ou seja, buscam ganhar aliados para as suas posições mediante a direção política e o consenso". (GRAMSCI, 2016, p. 128).

Nesse sentido, sociedade civil e o Estado são partes de uma mesma totalidade, mas se diferenciam pela forma como articulam a reprodução das relações de poder e a organização da vida social; e "é isso que torna o Estado uma instituição contraditória", já que "ao mesmo tempo em que exerce a dominação pura e simples, ele também usa de mecanismos e consenso para se legitimar perante o conjunto da sociedade, tendo, portanto, de atender demandas e necessidades das classes subalternas (PEREIRA, 2009, p. 298). Com efeito, é esta natureza contraditória do Estado que lhe permite legitimidade frente às classes sociais e à sociedade civil, já que elas the concedem o poder político para que este se coloque como o mediador social, tarefa que é intercedida por disputas políticas.

O envolvimento do Estado com as classes sociais e a sociedade civil expõe a sua natureza relacional, que o impede de ser um instrumento exclusivo de dominação de uma classe sobre a outra, mesmo tendo uma índole de classe e dominação contraditória. Este conteúdo específico do Estado qualifica-o como uma relação contraditória e de condensação que o impede de ser engessado e manipulado.

Esta qualificação é também particularizada pelas características de formação social de cada sociedade civil, que imprimem ao Estado variados tons de atendimento às demandas sociais e explica as mudanças de feições do Estado no decorrer do desenvolvimento histórico capitalista.

Por isso, a compreensão das mediações do Estado com as classes sociais deve considerar as particularidades de formação social da sociedade civil, uma vez que esta é um espaço da luta de classe e das forças populares democráticas que determinam "substancialmente os limites, as fronteiras e o conteúdo do Estado, das mudanças de sua forma”. (URRY, 1982, p. 102).

Mas isso não retira a natureza de classe do Estado. Resguardadas as particularidades de formação social, a natureza de classe do Estado burguês garante o predomínio das relações de produção sobre as forças produtivas, de modo a viabilizar a apropriação privada da produção que é realizada de maneira coletiva.

O Estado, portanto, é parte da correlação de forças inerentes às contradições de classes na sociedade burguesa gestadas na esfera produtiva desse sistema, configurando-se espaço de densidade e concentração dessas forças, extremamente necessário para que a dinâmica produtiva e reprodutiva do capital se mantenha. 


\section{Estado e classes sociais: entre a dominação das classes subalternas e a hegemonia das classes dominantes}

$\mathrm{Na}$ tarefa de assegurar a supremacia capitalista, a materialidade do Estado acentua a polarização das classes sociais e, assim, dificulta a organização da classe dominada, para mantê-las dominadas, ao mesmo tempo em que assume caráter universal, formal e impessoal, respaldado na relativa separação entre político e o econômico e entre ações coercitivas e de consenso exercitado no espaço da sociedade civil.

Tais ações correspondem às necessidades das particulares relações produtivas capitalistas e às lutas de classe, por meio de uma materialidade própria, e de aparelhos especializados e centralizados, de natureza política, responsáveis por um "agrupamento de funções anônimas, impessoais e formalmente distintas do poder econômico, cujo gerenciamento [...] de leis-regras", visa garantir "a total espoliação do trabalhador direto nas relações de produção capitalistas". (POULANTZAS, 1980, p. 60-61).

Entre essas ações, o Estado capitalista reforça a divisão social do trabalho, mais precisamente a divisão entre trabalho manual e trabalho intelectual. Esta separação é promovida pelo Estado, uma vez que os seus aparelhos assumem as atividades ligadas ao trabalho intelectual e se colocam distantes do trabalho manual, pelo fato de o Estado não atuar diretamente na produção capitalista. Essa dissociação, tão favorável ao capital, garante "a relação orgânica entre trabalho intelectual e dominação política, entre saber e poder" que, no Estado, se efetua de maneira mais acabada por ser, "ele [o] corolário e o produto desta divisão, ao deter um papel próprio em sua constituição e sua reprodução". (POULANTZAS, 1980, p. 63).

O domínio do trabalho intelectual pelo Estado capitalista é uma importante estratégia de hegemonia burguesa, visto que, por meio dele se estruturam e se formam um conjunto de ideologias responsáveis por difundir e manter os valores das classes dominantes, preservando, assim, o seu domínio.

Mandel chama a atenção desse processo no contexto do capitalismo tardio, mostrando a forte ação dos grupos empresariais junto à administração estatal, como parte de um processo de "articulação privada dos interesses de classe da burguesia a uma centralização crescente das decisões políticas no aparelho técnicoadministrativo do Estado [o que] leva a uma síntese da aliança pessoal entre grandes empresas e altos funcionários do governo". (MANDEL, 1982, p. 344-345).

Outro aspecto importante da ação do Estado na mediação com as classes sociais no capitalismo é o desencadeamento do processo de individualização e especialização. A materialidade do Estado capitalista, correspondendo às relações de produção e à divisão social do trabalho, implica processo de atomização e parcelarização do corpo político designando indivíduos, interpretados como pessoas jurídicas-políticas e sujeitos de liberdade.

A individualização corresponde à necessidade da produção capitalista, que é o despojamento dos meios de produção do trabalhador. Este despojamento tem que ser livre, desligado de uma rede de proteção solidária e de identidade e, nisto, o Estado tem papel fundamental, inclusive porque "é nessa individualização que se escora a materialidade institucional do Estado capitalista". (POULANTZAS, 1980, p. 73).

O Estado, nesse caso, não é mero mediador do processo de individualização, mas fator constitutivo da organização social do trabalho que produz "permanentemente fracionamento-individualização social". O Estado capitalista se materializa pela perspectiva individualista. Ele não trabalha com a premissa das classes sociais. Suas ações visam consagrar e institucionalizar "mônadas econômico-sociais em indivíduos-pessoas-sujeitos jurídicos e políticos", reforçando um chamariz ideológico individualista e fragmentado que se contrapõe às classes sociais, em vista não apenas de "mascarar e ocultar as relações de classe [...] mas também de contribuir ativamente para a divisão e isolamento (individualização) das massas populares". (POULANTZAS, 1980, p. 73).

Com a individualização, o Estado assume um caráter neutro e de árbitro social, porque se coloca como mediador dos interesses particulares de pessoas singulares, sem vínculos e identidades sociais. Essa postura superficial do Estado é fabricada pelo próprio Estado, por meio de um "conjunto de técnica de saber e de práticas de poder"; e com ela encobre-se o "solo originário das classes em sua especificidade capitalista". (POULANTZAS, 1980, p. 74).

A lei é outro aspecto importante das ações mais gerais do Estado capitalista que se relaciona com a individualização. Tal Estado é caracterizado como de direito e da lei. Mediante esta, ele detém o monopólio da violência e da guerra, que fazem parte de suas funções repressivas. 
Todavia, para além da coerção, a lei detém um papel importante na criação de estratégias de consenso, consentimento e dominação. Com ela, materializa-se e impõe-se a ideologia dominante, através da ocultação das "realidades político-econômicas; [...] e transpõe-se essas realidades para a cena política por meio de um mecanismo próprio de ocultação-inversão". Com a lei, ainda, são formalizadas e naturalizadas as relações econômicas e sociais que dão sustentação às classes dominantes, traduzindo, assim, "a representação imaginária da sociedade e do poder" dessas classes (POULANTZAS, 1980, p. 94). Com a lei, enfim, "o poder de um homem sobre o outro expressa-se na realidade como o poder do direito, isto é, como o poder de uma norma objetiva imparcial". (PACHUKANIS, 2017, p. 98).

Ou seja, a lei, cujo domínio é do Estado, cumpre, dessa forma, uma importante função de controle e submissão das classes sociais ao sistema dominante e se apresenta de maneira imparcial para a sociedade civil.

A lei é, sob esse aspecto, e paralelamente a seu lugar no dispositivo repressivo, um dos fatores importantes da organização do consentimento das classes dominadas, embora a legitimidade (o consentimento) não se identifique nem se limite a legalidade. As classes dominadas encontram na lei uma barreira de exclusão e igualmente a designação do lugar que devem ocupar. Lugar que é também de inserção na rede políticosocial, criadora de deveres-obrigações e também de direitos, lugar cuja posse imaginária tem consequências reais sobre os agentes. (POULANTZAS, 1980, p. 94).

Além disso, a lei, no capitalismo, instaura a individualização que ocasiona a fragmentação das classes sociais. Ela é própria da ossatura do Estado e cumpre com a tarefa de "despojamento total dos agentes da produção de seu poder intelectual em proveito das classes dominantes e de seu Estado" (POULANTZAS, 1980, p. 101).

A lei, personificada pelo Estado e naturalizada na sociedade civil, está diretamente relacionada e determinada pelas classes sociais e pelas lutas de classe, garantindo, assim, as necessidades das relações produtivas do capitalismo. É a lei que garante a regulamentação de uma relação desigual: os lugares das classes sociais e dos agentes que não lhe são formalmente ligados. Ela garante a submissão do trabalho ao capital, instaurando uma formalidade e igualdade superficial, em que "todos são livres e iguais diante da lei sob a condição de que todos sejam e tornem-se burgueses, o que a lei ao mesmo tempo permite e interdita". (POULANTZAS, 1980, p. 102).

E interdita porque, ainda que a lei cumpra, primordialmente, a tarefa dominadora, contraditoriamente ela responde às lutas de classe e garante certos benefícios às classes dominadas. Como uma mediação do direito capitalista, a lei regula o exercício do poder frente a estas classes: "face à luta da classe operária no plano político, esse direito organiza o quadro de um equilíbrio permanente de compromisso imposto às classes dominantes pelas classes dominadas". (POULANTZAS, 1980, p. 104).

Isso expõe novamente o caráter contraditório do Estado capitalista, ainda que este seja um Estado de classe e que seus aparelhos reproduzam estratégias de dominação de classe. Suas ações também, já visto, são funcionais às demandas das classes subalternas. E ao assumir essa feição formalista e neutra, suas funções respondem as pautas destas classes. Isso é assim porque, contraditoriamente, as ações impostas pelo direito e pela lei burguesa, especialmente a que trata das liberdades formais e abstratas, são também conquistas das classes populares, donde se entende que "esse papel da lei depende da relação de força entre as classes, e esboça também uma barreira ao poder das classes dominantes imposta pelas classes dominadas". (POULANTZAS, 1980, p. 104).

Todavia, nem só de coerção vive a prática do Estado; este desenvolve papéis diretamente relacionados com as classes fundamentais, as dominantes e dominadas, com principal intuito de manter a hegemonia da classe dominante.

Em conformidade com a sua natureza de classe, cabe ao Estado mediar as relações entre as frações da classe dominante e, entre estas e as classes dominadas balizar as inerentes lutas e disputas entre essas classes, organizando uma gama de ações que garanta o domínio do mercado e das relações de propriedade, o domínio político da classe dominante e o controle das classes dominadas.

Em relação às classes dominantes, um dos principais papéis estatais é o da organização do bloco no poder. Por meio de seus aparelhos repressivo, ideológico e econômico, o Estado garante a unidade política dessas classes, mantendo-as como classes dominantes, configurando-se, conforme Mandel (1982), em um 
"Estado capitalista total ideal". Isso quer dizer que a natureza de classe do Estado capitalista faz parte do núcleo estrutural desse Estado, independentemente da forma que este assuma.

Em relação às classes dominadas, o Estado visa, essencialmente, por meio de sua estrutura, "desorganizardividir continuamente as classes dominadas, polarizando-as para o bloco no poder" (POULANTZAS, 1980, p. 161), mediante variados acordos entre as classes dominadas e o bloco de poder; ou mais especificamente, por meio de ações que, contraditoriamente, se mostram de forma favorável às classes dominadas, mas que indicam os limites desse Estado às lutas dessa classe, visto que, ainda que seja funcional a elas, ele é um Estado burguês.

Nesse aspecto, Gramsci foi um dos autores que mais abordou o papel do Estado na relação com as classes dominadas, destacando especialmente ações que este passou a desempenhar junto às estas classes, que não se vinculavam ao aspecto coercitivo de dominação. Estas ações, desempenhadas no campo da sociedade civil, visam garantir um consenso, formando o "'homem coletivo' ou do "conformismo social", mediado pela "tarefa educativa e formativa do Estado, cujo fim é sempre o de criar novos e mais elevados tipos de civilização", em vista de "adequar a 'civilização' e a moralidade das mais amplas massas populares às necessidades do contínuo desenvolvimento do aparelho econômico de produção". (GRAMSCI, 2016, p. 23).

As construções teóricas de Gramsci, desenvolvidas no contexto de ampliação da democracia burguesa, mostraram que as estruturas do sistema capitalista exigiram novas formas de dominação e que essas foram mediadas pela esfera ideológica cuja materialidade era posta na sociedade civil conjuntamente e ultrapassando a sociedade política.

As ações ligadas à integração das classes dominadas são mediadas pela perpetuação da ideologia dos setores dominantes, a fim de que sejam aceitas pelos setores dominados, legitimando e naturalizando os processos de exploração que estão na essência da sociabilidade burguesa e que, mesmo não se utilizando do recurso da repressão direta, são elementos que garantem a sustentação do sistema.

Por isso, as ações desenvolvidas pelo Estado, nesse aspecto, foram caracterizadas por Gramsci como educativas, pois visavam manter e reproduzir o domínio e as estruturas econômicas por meio da construção da adesão na consciência das classes fundamentais. Com essas ações, as estratégias de manutenção das relações de dominação e consenso também foram mediadas pela direção política e ideológica, expressas e vivenciadas na sociedade civil, demonstrando outros aspectos estruturais que estão na base de sustentação da hegemonia capitalista. "Na realidade, o Estado deve ser concebido como 'educador' na medida em que tende precisamente a criar um novo tipo de civilização. Dado que se opera essencialmente sobre as forças econômicas, que se reorganiza e se desenvolve o aparelho de produção econômica". (GRAMSCI, 2016, p. 28).

Dentre as tarefas desempenhadas por esse Estado educador, destacam-se os programas de capacitação da força de trabalho para novos processos produtivos. Também no âmbito dessas funções educativas, cabe destacar a apropriação pelo Estado dos espaços educacionais e de cultura, transformando estes em aparelhos estatais de hegemonia, pois são considerados "serviços públicos intelectuais" (GRAMSCI, 2016, p. 187) que, aliados aos aparelhos privados de hegemonia ${ }^{1}$, são mediações importantíssimas para assegurar o domínio da classe hegemônica.

Também junto às classes dominadas, o Estado desempenha funções econômicas e sociais que visam, primordialmente, manter o controle dessa classe e a supremacia da classe dominante. A política social é, nesse processo, um importante instrumento de mediação dessa relação.

Envolvido, contraditoriamente, com a reprodução econômica capitalista, o Estado ampliou a sua interveniência no âmbito da reprodução social. As funções sociais do Estado, com vista a esta reprodução, o colocaram no cerne dos conflitos de classe, devendo responder a demandas e necessidades sociais sob a pressão da classe trabalhadora em sua luta contra a exploração e a dominação capitalista; respostas estas que desviam a centralidade de sua atenção às requisições burguesas, ainda que, contraditoriamente, as beneficiem por incidirem na reprodução da força de trabalho.

Em vista disso, no mesmo passo em que as funções sociais do Estado, particularmente nos países da Europa ocidental, implicaram avanços sociais para a classe trabalhadora, colocaram o Estado no centro da reprodução ampliada desta classe, em proveito do capital. E esses processos exigiram do Estado o exercício de sua ação condensatória.

Nessa construção condensatória, cabe ao Estado considerar e mediar os variados interesses das frações da classe dominante. A ação organizativa e impositiva desta classe, por meio do Estado, é possibilitada pela 
"autonomia relativa [deste] em relação a tal ou qual fração e componente desse bloco, em relação a tais ou quais interesses particulares". (POULANTZAS, 1980, p. 155).

Esta autonomia relativa é parte constitutiva do Estado e resulta do relativo afastamento deste dos meios de produção, permitindo-lhe o desenvolvimento de uma independência relativa frente às frações da classe burguesa, para garantir os interesses gerais da classe burguesa (POULANTZAS, 1980, p. 146).

Na relação com as classes dominadas, o Estado também exerce a sua autonomia relativa, mas sempre visando garantir a hegemonia da classe dominante. Por meio dessa autonomia relativa, são realizados compromissos materiais entre o bloco no poder e as classes subalternas.

Nesse processo, o Estado capitalista, traduz os interesses das classes dominantes, não de maneira harmônica e mecânica, mas por meio de relações de força, disputas e condensação de interesses entre classes e frações de classes.

A autonomia relativa do Estado e das suas instituições, cientes de sua capacidade de condensar relações de forças, não reduz o seu caráter "constituído-dividido de lado a lado pelas contradições de classe". As lutas de classe não são uma variante externa que atravessa o Estado. As "contradições de classe constituem o Estado, presentes na sua ossatura material, e armam, assim, sua organização: a política do Estado é o efeito de seu funcionamento no seio do Estado". (POULANTZAS, 1980, p. 152).

Como condensação de relações de forças entre classes e frações de classe, o Estado absorve as contradições e disputas das frações da classe dominante. Ele condensa a relação de forças entre os blocos de poder e entre as frações da classe dominante, visando assegurar a hegemonia do sistema capitalista, preservando a sua organização, não como um árbitro das contradições de classe, mas, "bem ao contrário, é o jogo dessas contradições na materialidade do Estado que torna possível, por mais paradoxal que possa parecer, a função de organização do Estado". (POULANTZAS, 1980, p. 153).

No âmbito das classes dominadas, o Estado também absorve as lutas de classes cumprindo com o mesmo objetivo de manter a hegemonia burguesa; mas, nesta relação com as classes dominadas, ele assume a feição de um bloco monolítico isolado destas classes, acolhendo as contradições sociais do capitalismo, como se estas fossem exteriores a ele que, como um agente neutro, caberia gerenciá-las.

Esta condição também responde pelo relativo afastamento do Estado dos meios de produção que desencadeiam uma estrutura hierárquica e burocrática, a qual "não têm por simples objetivo afrontar, cara a cara, as classes dominadas, mas manter e reproduzir no seio do Estado a relação dominação-subordinação: o inimigo de classe está sempre no Estado" (POULANTZAS, 1980, p. 163).

Essa condição apartada também responde à falsa dissociação entre Estado e sociedade civil que encobre a presença do Estado na constituição e reprodução das classes sociais e camufla a desigualdade gerada na esfera econômica, transferindo para o Estado a responsabilidade para com as contradições sociais do sistema. Contudo,

O Estado não pode acreditar na impotência interior da sua administração, isto é, de si mesmo. Ele pode descobrir apenas defeitos formais, casuais, da mesma, e tentar remediá-los. Se tais modificações são infrutíferas, então o mal social é uma imperfeição natural, independente do homem, uma lei de Deus, ou então a vontade dos indivíduos particulares é por demais corrupta para corresponder aos bons objetivos da administração (MARX, 2010, p. 08).

Essa falsa feição monolítica cumpre com a tarefa de invisibilizar as contradições e a exploração das relações produtivas do sistema capitalista, transferindo as contradições deste sistema para a dimensão política estatal, reforçando a compreensão exterior do Estado, no qual "as contradições entre classes dominantes e classes dominadas permaneceriam contradições entre o Estado e as massas populares exteriores ao Estado" (POULANTZAS, 1980, p. 162) isso, além de reforçar a premissa de um Estado neutro e à parte das classes sociais como se este apenas assistisse as lutas de classes, sem estar presente nelas, ou como se a "luta das classes dominadas não seria uma luta presente no Estado, consistindo simplesmente em pressões sobre o Estado". (POULANTZAS, 1980, p. 162).

Nesse sentido, atribuir as contradições sociais à ineficiência administrativa do Estado, restringe essas contradições ao campo político e expõe o "equívoco metodológico que toma a esfera política, que é parte da totalidade social, como fundamento e princípio da inteligibilidade dos fenômenos sociais". (TONET, 2010, p. 03). 
A implicação desses equívocos é a transmutação da contradição fundamental, exploração do trabalho, da dimensão econômica para a política, situando "a raiz dos males sociais [...] em todos os lugares, menos onde ela efetivamente se encontra e que o remédio sempre é através de reformas e nunca a revolução social". (TONET, 2010, p. 03).

Além disso, reduzir as contradições sociais ao campo político, precisamente no Estado, é negar a essência exploradora do sistema capitalista porque os males sociais não podem ser explicados e enfrentados somente pela dimensão política. Esta é limitada porque não toca na essência da questão - que é a exploração do trabalho na esfera produtiva.

As classes sociais e as lutas de classe compõem o Estado capitalista, o que não significa que o Estado as assumiu, mas que, ao contrário, é produto destas. Estas lutas não estão fora do poder, mas inscritas nos aparelhos e na estrutura do Estado, ainda que assumam postura meramente supraestrutural. A assunção desta postura confere ao Estado caráter mediador formal e administrativo, que expõe sua limitação frente às demandas sociais, impedindo-o de explicar e resolvê-las; e quando não o impede, as explicações e resoluções são procuradas "ou em leis da natureza, que nenhuma força humana pode comandar, ou na vida privada, que é independente dele, ou na ineficiência da administração, que depende dele" (MARX, 2010, p. 07).

Por conseguinte, ainda que o Estado seja o espaço de condensação relações de forças, as lutas populares no Estado se materializam de maneira específica, "sob a forma de focos de oposição ao poder das classes dominantes" (POULANTZAS, 1980, p. 164).

A inscrição das lutas populares no Estado não significa que, através do domínio deste, a condição de classe dominante será superada, como se no Estado predominasse uma disputa igualitária entre o poder da classe dominante e o da classe dominada.

Tal processo não é possível em razão da natureza de classe do Estado que se expressa em todo o seu arcabouço material e garante o controle das classes dominadas pela classe dominante, por meio de "mecanismos internos de reprodução da relação dominação-subordinação, [que] assegura a presença de classes dominadas em seu seio, embora exatamente como classes dominadas" (POULANTZAS, 1980, p. 164).

Mesmo assim, o Estado, como relação social é um espaço favorável de relações de forças (GRAMSCI, 2016), pois é por meio das relações de forças no Estado que se torna possível desenvolver estratégias que transcendam uma situação política e econômica objetiva, ou melhor, mesmo situado na realidade objetiva do domínio econômico, é preciso transcender a esse imediatismo, criando relações de forças e políticas favoráveis à ação revolucionária.

Entretanto, ainda que exista uma correlação de forças dentro do Estado em favor das classes populares, o domínio da classe burguesa se restabelece e a solução para isso não se encontra na tomada dos aparelhos de Estado pelas massas populares, uma vez que a presença destas classes no Estado não modifica a sua natureza de dominação de classes. A ação das massas populares no seio do Estado é condição necessária para sua transformação, mas não é o bastante, já que o "Estado é o lugar de organização estratégica da classe dominante em sua relação com as classes dominadas". (POULANTZAS, 1980, p. 169).

Dessa feita, embora o Estado seja permeável às lutas populares, ele não sucumbe a elas; não rompe com a sua natureza de classe, posto que a tem na sua materialidade institucional. Mas estas lutas são uma mediação importante para a superação do capitalismo e da sua forma política, na medida em que for desalienada das relações de dominação ideológicas, educativas e morais, que resguardam este sistema. Por isso, Marx defendia a "desalienação da sociedade civil [para que esta possa] levar à extinção do Estado, extinção que é entendida como recuperação pela sociedade dos poderes alienados por aquele". (ACANDA, 2006, p. 138).

\section{Considerações finais}

Com base nas produções teóricas de autores vinculados à tradição marxista, abordou-se, nesta reflexão, a dialética relação Estado e classes sociais sob o modo de produção capitalista.

Apreendeu-se que o Estado capitalista, como forma política deste sistema, configura-se como um modelo peculiar de dominação de classes que repassa o comando da coerção para o Estado e não diretamente para a classe dominante. Tal processo desencadeia uma dinâmica que, à primeira vista, poderia indicar restrição da ação estatal ao campo político, mas que inscreve, na verdade, o Estado na totalidade das relações capitalistas. 
Nesse processo particular de dominação, o Estado é atravessado pelas lutas de classe. Essas, contraditoriamente, impedem que o Estado seja um ente exclusivo de classe, mas revela a sua natureza relacional contraditória, haja vista que o Estado, ao interagir com as classes sociais fundamentais do capitalismo, deixa de ser um ente rígido e engessado.

Contudo, isso não retira a condição de classe do Estado, visto que a sua dimensão relacional e contraditória pode ampliar o leque de interação com a sociedade e, assim, oferecer respostas e mediações progressistas às demandas da classe trabalhadora, a exemplo das políticas sociais. Porém, essas medidas se dão no limite da dinâmica produtiva do sistema capitalista, a exploração do trabalho.

Mesmo que circunscritas aos limites do sistema capitalista, as dimensões relacional e contraditória do Estado são fundamentais para a melhoria das condições de existência das classes dominadas. Para tanto, são necessárias que as lutas de classe pressionem o Estado para o alargamento dessa extensão relacional, já que esta dimensão prescinde de avanços e princípios democráticos. Ainda assim, assevera-se que a tomada do Estado não deve ser o objetivo primordial das lutas das classes subalternas, visto que a relação de dominação do Estado com as classes dominadas, ainda que contraditória, é uma das razões de ser desse Estado.

\section{Referências}

ACANDA, J. L. Sociedade Civil e Hegemonia. Rio de Janeiro: Ed. da UFRJ, 2006.

GRAMSCI, A. Cadernos do Cárcere. Rio de Janeiro: Civilização Brasileira, 2016.

IANNI, O. Classe e nação. Petrópolis: Vozes, 1986.

MANDEL, E. O capitalismo tardio. São Paulo: Abril Cultural, 1982.

MARX, K. Glosas Críticas marginais ao artigo "O rei da Prússia e a reforma social” de um prussiano. (Introdução de Ivo Tonet). São Paulo: Expressão Popular, 2010.

OSORIO, J. O Estado no Centro da Mundialização: a sociedade civil e o tema do poder. São Paulo: Expressão Popular, 2019.

PACHUKANIS, E. A teoria geral do direito e o marxismo. São Paulo: Boitempo, 2017.

PEREIRA, P. A. P. Estado, sociedade e esfera pública. In: ASSOCIAÇÃO BRASILEIRA DE ENSINO E PESQUISA EM SERVIÇO SOCIAL (ABEPSS). Serviço Social: direitos sociais e competências profissionais. Brasília: CFESS/ABEPSS, 2009. p. 285-300.

POULANTZAS, N. O Estado, o poder, o socialismo. Rio de Janeiro: Graal, 1980.

TONET, I. A propósito de "Glosas Críticas”. São Paulo: Expressão Popular, 2010.

URRY, John. Anatomia das sociedades capitalistas: a economia, a sociedade civil e o estado. Rio de Janeiro, Ed. Zahar, 1982.

\section{Nota}

1 "Organismos sociais coletivos voluntários e relativamente autônomos e face da sociedade política". (GRAMSCI, 2016, p. 129).

\section{Liliam dos Reis Souza Santos}

E-mail: liliamsouza@unb.br

Doutorado em Política Social pelo Programa de Pós-Graduação em Política Social da Universidade de Brasília (UnB)

Professora Adjunta do Departamento de Serviço Social da Universidade de Brasília (UnB)

\section{UnB}

Campus Universitário Darcy Ribeiro, Instituto Central de Ciências

(ICC NORTE - Asa Norte, Brasília - DF)

CEP: 70910-900

\section{Agradecimentos}

Este trabalho foi construído a partir de minha tese de doutorado. Dessa forma, agradeço à minha orientadora, Dra.
Potyara Pereira, pelo seu apoio e contribuição ao longo do doutoramento, ao Departamento de Serviço Social/UnB pelo afastamento para a conclusão da tese e, por fim, à minha filha, 
Maria Beatriz e meu esposo, Erivelton, que são minha base, refúgio e inspiração.

Agência financiadora

Não se aplica.

Contribuições das autoras

Não se aplica.
Aprovação por Comitê de Ética e consentimento para participação

Não se aplica.

Consentimento para publicação

Consentimento da autora.

Conflito de interesses

Não há conflito de interesses. 